\title{
SPACE-TIME TAYLOR-HOOD ELEMENTS FOR INCOMPRESSIBLE FLOWS ${ }^{1}$
}

\author{
Douglas R.Q. Pacheco*, Olaf Steinbach \\ Institute of Applied Mathematics, Graz University of Technology, Graz, Austria \\ Graz Center of Computational Engineering, Graz University of Technology, Graz, Austria \\ *Corresponding author: pacheco@math.tugraz.at
}

\begin{abstract}
Space-time variational methods differ from time-stepping schemes by discretising the whole space-time domain with finite elements. This offers a natural framework for flow problems in moving domains and allows simultaneous parallelisation and adaptivity in space and time. For incompressible flows, the usual approach is to employ the same polynomial order for velocity and pressure, which requires the use of stabilisation techniques to compensate for the inf-sup deficiency of such pairs. In the present work, we extend to the space-time formulation the idea of the popular Taylor-Hood element for the (Navier-)Stokes equations. By using quadratic interpolation for velocities and linear for pressure, in both space and time, we attain a stable finite element method which provides optimal convergence for pressure, velocity and stresses.
\end{abstract}

Key words: Computational Fluid Dynamics, Finite Element Method, Space-time methods, Incompressible flows, Stable finite elements

\section{INTRODUCTION}

In variational formulations for time-dependent flow problems, the time interval and the spatial domain are typically treated in very different manners. The most popular approach is the method of lines (Marx, 1994; Dettmer \& Peric, 2003): a finite element/volume discretisation in space, followed by a finite difference or Runge-Kutta discretisation in time. Despite simple in design, those methods have a serious limitation, namely, the requirement of uniformin-space time steps. This means that a temporal refinement that would perhaps be needed only locally is instead applied to the entire spatial domain, thereby unnecessarily increasing the global number of degrees of freedom. In that context, space-time methods aim to overcome the limitations of time-marching schemes by offering a unified approach where time and space are treated in an equal - or at least similar - manner.

The vast majority of works dealing with spacetime finite element methods for fluid flows employ a discontinuous Galerkin (DG) method in time (e.g., Behr \& Tezduyar, 1994; Behr, 2001; Behr et al., 2006; Neumüller \& Steinbach, 2011; Pauli \& Behr, 2017; van der Vegt \& Sudirham, 2008). This allows sequential solution procedures where the space-time domain is divided in the time direction into slabs: the solution obtained in the first (initial) time slab is weakly transmitted onto the second one, and so on. The main shortcomings of such DG methods are the increased number of degrees of freedom and the need for looping on internal faces. In the present work, however, we employ a continuous finite element discretisation in both space and time. The idea is to allow for fully unstructured space-time meshes, thereby enabling adaptive refinement strategies simultaneously

${ }^{1}$ The paper presented during YIC 2019, ECCOMAS Young Investigators Conference held in Kraków, Poland on September 1-6, 2019 
in space and time, as well as parallel solution strategies. At the present stage, however, we still consider structured meshes as a proof of concept.

To the best of the authors' knowledge, all works published in space-time finite elements for fluid flows employ stabilised methods, i.e., introducing additional terms into the variational formulation in order to compensate for the use of inf-sup-deficient velocity-pressure pairs. In this work, we propose a stable mixed space-time finite element method for the (Navier-)Stokes system by extending the idea of TaylorHood elements to the space-time setting. Numerical results reveal stability and optimal convergence rates for pressure, velocity, and stresses.

\section{FORMULATION}

As a model problem, we consider the homogeneous Dirichlet case for the incompressible NavierStokes problem in a time interval $(0, T)$ and a bounded Lipschitz spatial domain $\Omega \mathrm{C} \mathbb{R}^{d}, d=2$ or 3 :

$\partial_{t} \boldsymbol{u}+\left(\nabla_{\mathrm{x}} \boldsymbol{u}\right) \boldsymbol{u}-R^{-1} \Delta_{\mathrm{x}} \boldsymbol{u}+\nabla_{x} p=\boldsymbol{g}$ in $Q$,

$\nabla_{x} \cdot \boldsymbol{u}=0$ in $Q$,

$\boldsymbol{u}=\mathbf{0}$ on $\partial \Omega \times(0, T)$,

$\boldsymbol{u}=\mathbf{0}$ at $t=0$

where $\boldsymbol{u}$ is the flow velocity, $p$ is the pressure, $\boldsymbol{g}$ is a volumetric force, $R$ is the Reynolds number and $Q:=$ $\Omega \times(0, T)$ is the space-time domain. Our space-time variational formulation reads: Given $\boldsymbol{g} \in \mathrm{Z}$ ', find $(\boldsymbol{u}, p)$ $\in X \times Y$ such that:

$\int_{0 \Omega}^{T} \int_{\Omega}\left(\partial_{t} \boldsymbol{u} \cdot \boldsymbol{v}+\left[\left(\nabla_{x} \mathbf{u}\right) \mathbf{u}\right] \cdot \boldsymbol{v}+\left(R^{-1} \nabla_{x} \boldsymbol{u}\right): \nabla_{x} \boldsymbol{v}-p \nabla_{x} \cdot \boldsymbol{v}\right) \mathrm{d} \Omega \mathrm{d} t$

$=\int_{0 \Omega}^{T} \int_{\Omega} \cdot \boldsymbol{v} \mathrm{d} \Omega \mathrm{d} t$,

$\int_{0 \Omega}^{T} \int_{\Omega}\left(q \nabla_{\mathrm{x}} \cdot \boldsymbol{u}\right) \mathrm{d} \Omega \mathrm{d} t+\int_{0}^{T}\left(\int_{\Omega} q \mathrm{~d} \Omega \int_{\Omega} p \mathrm{~d} \Omega\right) \mathrm{d} t=0$

is satisfied for all $(v, q) \in Z \times Y$, with the spaces being $Y=L^{2}(Q), Z=\left[L^{2}\left(0, T ; H_{0}^{1}(\Omega)\right)\right]^{d}$ and $X=\left\{\boldsymbol{w} \in \mathrm{Z}: \partial_{\mathrm{t}} \boldsymbol{w}\right.$ $\in\left[L^{2}\left(0, T ; H^{-1}(\Omega)\right)\right]^{d}$ and $\left.\left.\boldsymbol{w}\right|_{t=0}=\mathbf{0}\right\}$. The integral added to the incompressibility equation enforces the scaling $\int_{\Omega} p \mathrm{~d} \Omega=0$ for all $t$.

Although the continuous formulation is of PetrovGalerkin type, in the discrete case we follow a stand- ard Bubnov-Galerkin approach with the same globally continuous trial and test functions. The spacetime domain is discretised with prismatic elements, that is, we have an arbitrary simplicial mesh in space which is extruded in the time direction. In order to obtain stability, we introduce space-time TaylorHood elements: globally continuous second- and first-order interpolations - in both space and time for velocity and pressure, respectively. Figure 1 illustrates such an element for $d=2$.

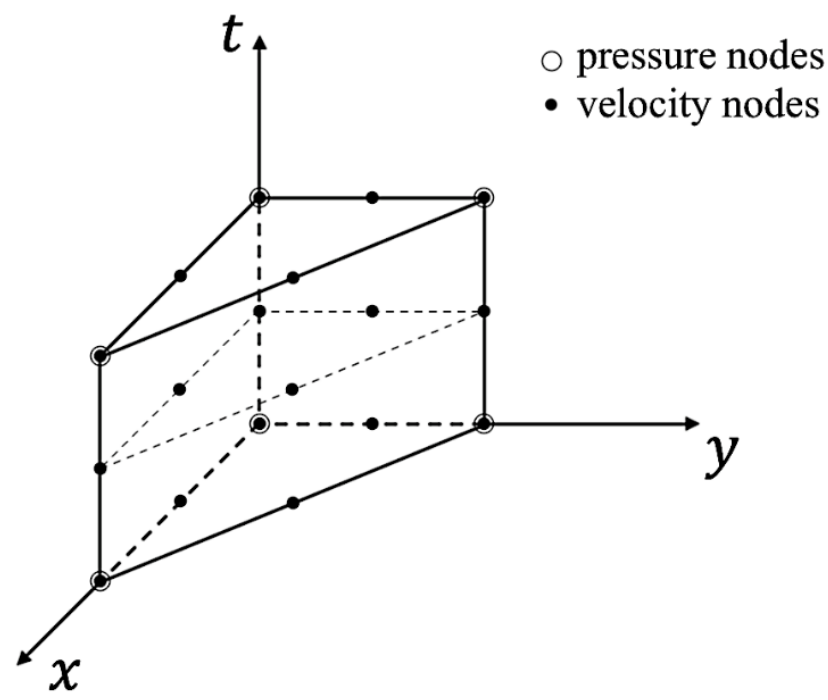

Fig. 1. Prismatic space-time Taylor-Hood element for two spatial dimensions $(d=2)$.

\section{NUMERICAL EXAMPLES}

In order to allow computation of approximation errors, we tackle problems with known analytical solutions. The pressure scaling integral in equation (2) is replaced by $\int_{0}^{T}\left[\left.(q p)\right|_{x=0}\right] \mathrm{d} t$, which enforces $p=0$ at $\boldsymbol{x}=\mathbf{0}$ for all $t$. This is possible since we are using finite element decompositions in which $\left.(q p)\right|_{x=0}$ is well defined.

For the two-dimensional examples, we consider the initial mesh shown in figure 2 (left), and four consecutive uniformly refined meshes, the finest of which can be seen in figure 2 (right). For the threedimensional case, the spatial domain is discretised into tetrahedra, and the space-time elements are constructed by extruding the spatial mesh in time, respecting the polynomial orders of the Taylor-Hood space. Since $d=3$ leads to a four-dimensional problem, and, on top of that, introduces an additional velocity component, the number of degrees of freedom in the system grows rapidly with every refinement 

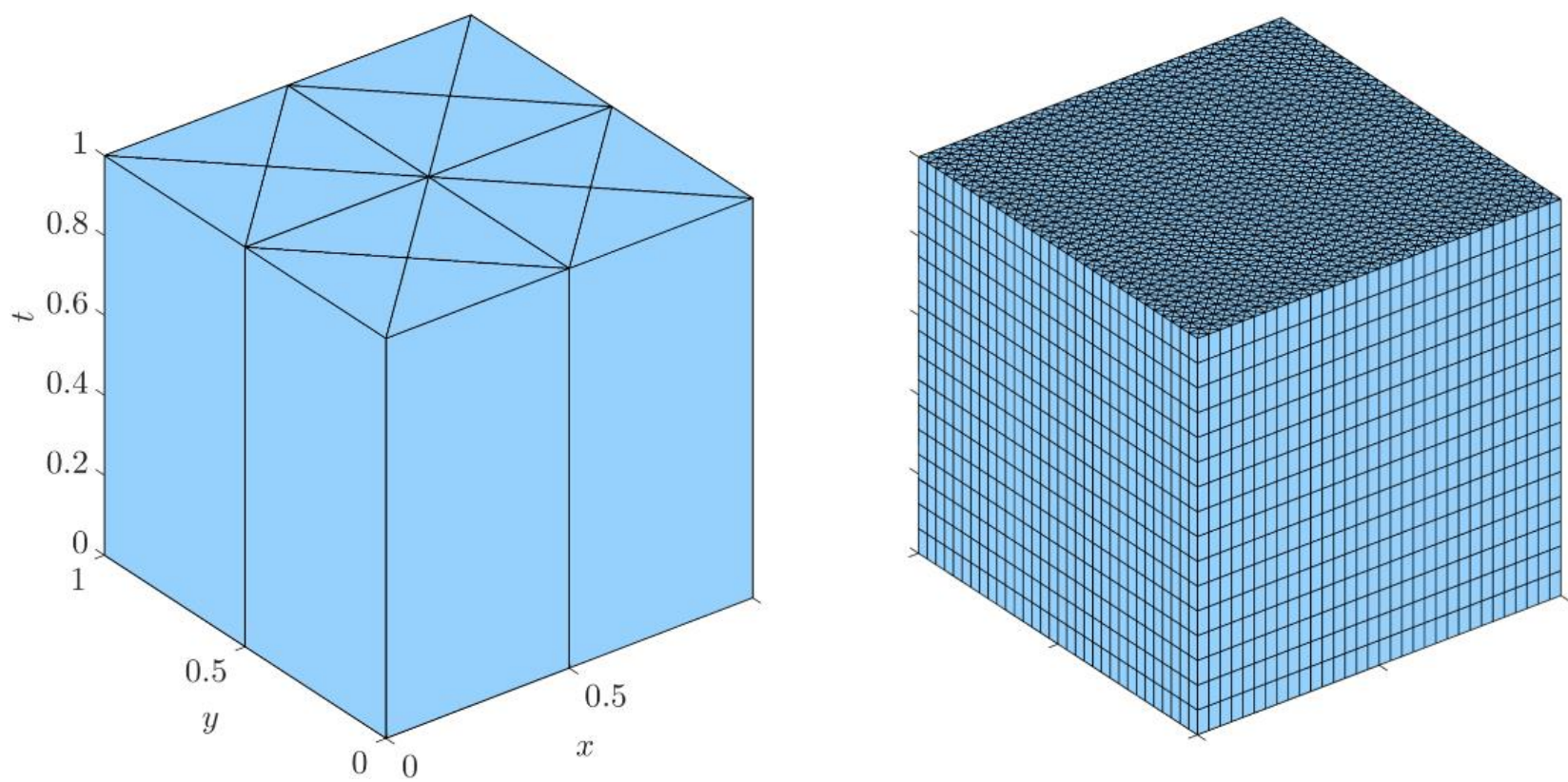

Fig. 2. Coarsest and finest space-time meshes used for the two-dimensional examples.

step. Therefore, we consider only three consecutive meshes for this example. The coarsest one has $192 \mathrm{el}-$ ements and is constructed from the spatial mesh shown in figure 3 , with the time interval divided uniformly into two. The finest mesh considered has 49152 elements. The next refinement level would have 786432 elements and 7.5 million degrees of freedom, which exceeds the memory limitations of the hardware used $\left(2 \times\right.$ Xeon ${ }^{\circledR}$ E5-2630 v3, 16x2.40 GHz, 256 GB DDR4 RAM).

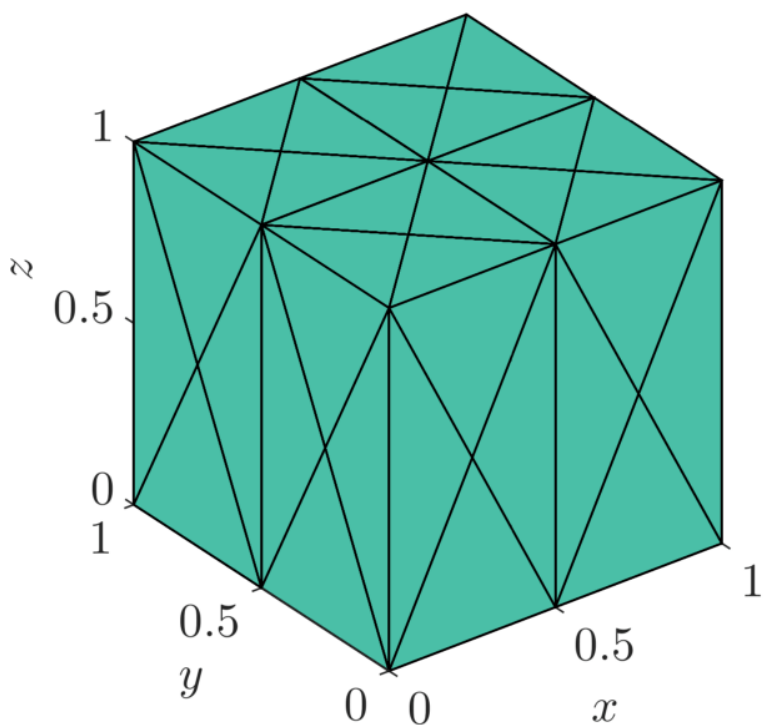

Fig. 3. Coarsest spatial mesh used in the three-dimensional numerical example.

\subsection{Stokes equations in two dimensions}

As a first example, we consider the Stokes system in $Q=(0,1)^{3}, R=1$, homogeneous Dirichlet boundary conditions and body force $\boldsymbol{g}=\boldsymbol{g}_{t}+\boldsymbol{g}_{x}+\boldsymbol{g}_{p}$, with:

$\boldsymbol{g}_{t}=\left(\begin{array}{l}x^{2} e^{-t}(x-1)^{2}\left(4 y^{3}-6 y^{2}+2 y\right) \\ -y^{2} e^{-t}(y-1)^{2}\left(4 x^{3}-6 x^{2}+2 x\right)\end{array}\right)$

$\boldsymbol{g}_{x}=$

$\left(\begin{array}{l}\left(1-e^{-t}\right)(4-8 y)\left(3 x^{4}-6 x^{3}-6 x^{2} y^{2}+3 x^{2}-6 x y^{2}+6 x y+y^{2}-y\right) \\ \left(1-e^{-t}\right)(8 x-4)\left(3 y^{4}-6 y^{3}-6 x^{2} y^{2}+3 y^{2}-6 y x^{2}+6 x y+x^{2}-x\right)\end{array}\right)$

$\boldsymbol{g}_{p}=\left(\begin{array}{c}t^{2}+y t^{3} e^{-x y t} \\ x t^{3} e^{-x y t}\end{array}\right)$

The corresponding analytical solution is:

$\boldsymbol{u}=\left(\begin{array}{l}\left(e^{-t}-1\right) x^{2}(x-1)^{2}\left(4 y^{3}-6 y^{2}+2 y\right) \\ \left(1-e^{-t}\right) y^{2}(y-1)^{2}\left(4 x^{3}-6 x^{2}+2 x\right)\end{array}\right)$

$p=\left(1+x-e^{-x y t}\right) t^{2}$

The error results are shown in figure 4 and reveal important aspects of the space-time Taylor-Hood element. First, the pressure can be seen to converge optimally, that is, quadratically in the $L^{2}(Q)$-norm. As for the velocity, we observe an interesting behaviour: second-order convergence of the spatial gradient, and first-order convergence of the temporal gradient. A priori error estimates in $H^{1,0}(Q):=L^{2}\left(0, T ; H^{1}(\Omega)\right)$ follow as in (Steinbach, 2015); error estimates in $H^{2,1}(Q)$ 
for globally quasi-uniform meshes follow by using an approximation property in $H^{2,1}(Q)$ and an inverse inequality.

Not only from the theoretical point of view, but also from a practical standpoint, these convergence orders can be seen as optimal. Firstly, because all the linear terms of the strong residual of the momentum equation, namely $\partial_{t} \boldsymbol{u}, R^{-1} \Delta_{x} \boldsymbol{u}$ and $\nabla_{x} p$, shall converge with the same order. The computation of the elementwise strong residual is necessary, for instance, in the stabilisation of convection-dominated NavierStokes flows. Secondly, $p$ and $\nabla_{x} \boldsymbol{u}$ converging quadratically leads to quadratic convergence of the Cauchy stress tensor, which is of critical importance in practical applications such as hemodynamics and fluid-structure interaction. Furthermore, since $\partial_{\boldsymbol{t}} \boldsymbol{u}$ represents just an acceleration and is not used in most applications, its "low-order" convergence has no negative impact on the method.

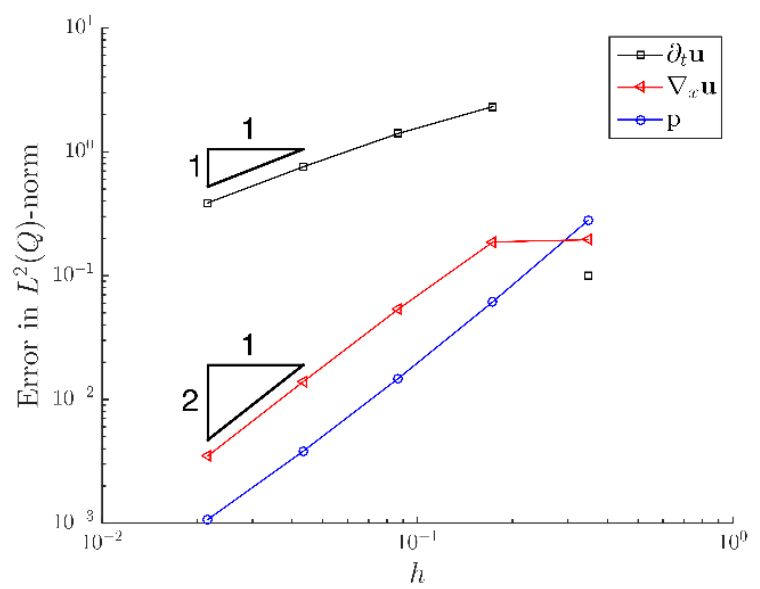

Fig. 4. Convergence plot for two-dimensional Stokes considering uniform refinement.

\subsection{Navier-Stokes equations in two dimensions}

As a second numerical example we consider the Taylor-Green vortex, which is a classical benchmark case for transient Navier-Stokes computations. In the unit space-time cube $Q=(0,1)^{3}$ and with $\boldsymbol{g}=\mathbf{0}$, the analytical solution is:

$\boldsymbol{u}=\left(\begin{array}{c}\sin \pi x \cos \pi y F(t) \\ -\sin \pi y \cos \pi x F(t)\end{array}\right)$

$p=-\frac{1}{2}\left(\sin ^{2} 2 \pi x+\sin ^{2} 2 \pi y\right) F^{2}(t)$

where: $F(t)=\exp \left(\frac{-2 \pi^{2} t}{R}\right)$. Figure 5 shows the error

plot for $R=100$. The pressure converges quadratically, as expected, and so does the velocity in the $H^{1}(Q)$ semi-norm. In this case, also the temporal gradient of $\boldsymbol{u}$ is converging quadratically, which is higher than expected.

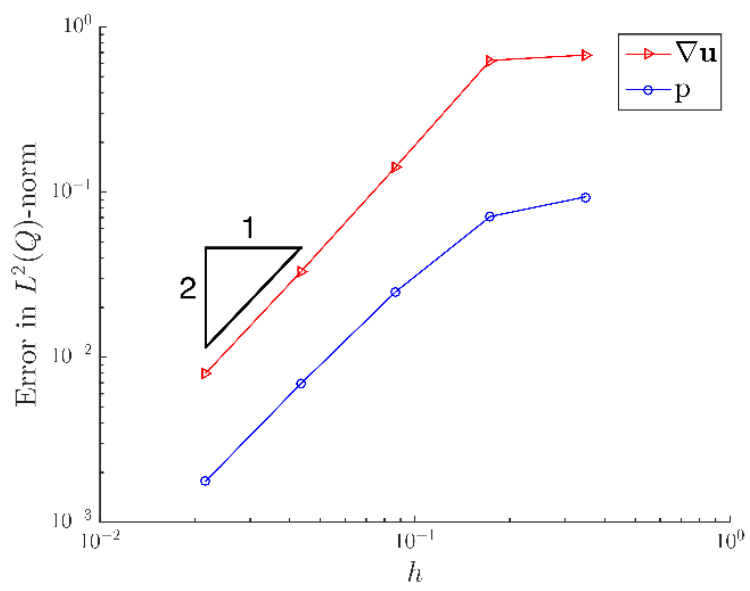

Fig. 5. Convergence plot for the Taylor-Green problem considering uniform refinement.

\subsection{Stokes equations in three dimensions}

We now tackle a spatially three-dimensional problem, meaning four dimensions in the space-time setting. The Stokes system is considered in the unit hypercube $Q=(0,1)^{4}$ and with $R=1$, homogeneous Dirichlet boundary conditions and body force $\boldsymbol{g}=\boldsymbol{g}_{t}+$ $\boldsymbol{g}_{x}+\boldsymbol{g}_{p}$, with: 


$$
\begin{aligned}
& \boldsymbol{g}_{t}=\left(\begin{array}{c}
2 x^{2} y e^{-t}(x-1)^{2}\left(z^{2}-z\right)\left(2 y^{2}-3 y+1\right) \\
2 x y^{2} e^{-t}(y-1)^{2}\left(z-z^{2}\right)\left(2 x^{2}-3 x+1\right) \\
0
\end{array}\right) \\
& \boldsymbol{g}_{x}=\left(\begin{array}{c}
4\left(e^{-t}-1\right)(2 y-1)\left(\left(z^{2}-z\right)\left(3\left(x^{2}-x\right)^{2}+\left(6\left(x^{2}-x\right)+1\right) y^{2}-6\left(x^{2}-x\right) y-y\right)+\left(y^{2}-y\right)\left(x^{2}-x\right)^{2}\right) \\
4\left(1-e^{-t}\right)(2 x-1)\left(\left(z^{2}-z\right)\left(3\left(y^{2}-y\right)^{2}+\left(6\left(y^{2}-y\right)+1\right) x^{2}-6\left(y^{2}-y\right) x-x\right)+\left(x^{2}-x\right)\left(y^{2}-y\right)^{2}\right) \\
0
\end{array}\right) \\
& \boldsymbol{g}_{p}=\left(\begin{array}{c}
0 \\
0 \\
e^{-t}(1-2 z)
\end{array}\right)
\end{aligned}
$$

The error plot in figure 6 reveals a similar convergence behaviour as in the two-dimensional case.

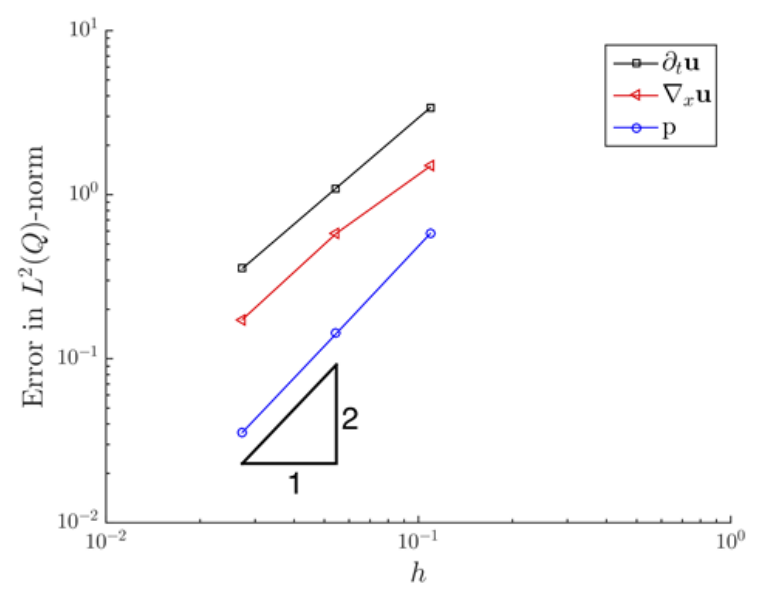

Fig. 6. Convergence plot for three-dimensional Stokes considering uniform refinement.

\section{CONCLUDING REMARKS}

In this work we have presented a stable spacetime finite element formulation for the incompressible Navier-Stokes equations. By extending to the space-time setting the idea of compatible polynomial orders from the Taylor-Hood element, we attain a stable mixed finite element scheme that does not require any stabilisation techniques for diffusion-dominated problems and yields optimally convergent solutions. We have further presented numerical examples in two and three dimensions, demonstrating optimal convergence orders. A more detailed numerical analysis must be done to prove stability of the proposed scheme, and to derive optimal error estimates as experienced in the numerical examples. This includes, in addition to the prismatic space-time Taylor-Hood elements, the use of simplicial elements in the spacetime domain. In order to derive adaptive mesh refinement, we may use appropriate a posteriori residualbased error estimators. For an efficient solution of the resulting large-scale algebraic systems, it is crucial to employ parallel strategies such as domain decomposition and "parareal in time" methods (Fischer et. al., 2005). The combination of all these techniques will result in more efficient simulation tools (Steinbach \& Yang, 2019) to handle today's challenging problems - not only in fluid mechanics.

\section{ACKNOWLEDGMENTS}

The authors acknowledge Graz University of Technology for the financial support of the Lead-project: Mechanics, Modeling and Simulation of Aortic Dissection.

\section{REFERENCES}

Behr, M., Tezduyar, T.E., 1994, Finite element solution strategies for large-scale flow simulations, Comput. Methods Applied. Mech. Engrg., 112, 3-24.

Behr, M., 2001, Stabilized space-time finite element formulations for free-surface flows, Commun. Numer. Meth. Engng., 17, 813-819.

Behr, M., Arora, D., Coronado, O.M., Pasquali, M., 2006, Models and finite element techniques for blood flow simulation, Int. J. Comput. Fluid D., 20, 175-181.

Dettmer, W., Peric, D., 2003, An analysis of the time integration algorithms for the finite element solutions of incompressible Navier-Stokes equations based on a stabilised formulation, Comput. Methods Applied. Mech. Engrg., 192, 1177-1226.

Fischer, P.F., Hecht, F., Maday, Y., 2005, A parareal in time semi-implicit approximation of the Navier-Stokes equations, In: Barth T.J. et al. (eds) Domain Decomposition Methods in Science and Engineering. Lecture Notes in 
Computer Science and Engineering, 40, Springer, Berlin, Heidelberg, 433-440.

Marx, Y.P., 1994, Time integration schemes for the unsteady Incompressible Navier-Stokes equations, J. Comput. Phys., 112, 182-209.

Neumüller, M., Steinbach, O., 2011, Refinement of flexible space-time finite element meshes and discontinuous Galerkin methods, Comput. Visual. Sci., 14, 189-205.

Pauli, L., Behr, M., 2017, On stabilized space-time FEM for anisotropic meshes: Incompressible Navier-Stokes equations and applications to blood flow in medical devices, Int. J. Numer. Meth. Fl., 85, 189-209.

Steinbach, O., 2015, Space-time finite element methods for parabolic problems, Comput. Methods Appl. Math., 15, 551-566.

Steinbach, O., Yang, H., 2019, Space-time finite element methods for parabolic evolution equations: Discretization, a posteriori error estimation, adaptivity and solution, In: Langer, U., Steinbach, O. (eds) Space-time Methods. Applications to Partial Differential Equations, Radon Series on Computational and Applied Mathematics, 25, de Grutyer, Berlin, 2017-4248.

van der Vegt, J.J., Sudirham, J.J., 2008, A space-time discontinuous Galerkin method for the time-dependent Oseen equations, Appl. Numer. Math., 58, 1892-1917.

\section{CZASO-PRZESTRZENNE ELEMENTY TYLORA- HOODA DLA NIEŚCIŚLIWYCH PRZEPLYWÓW}

\section{Streszczenie}

Przestrzenno-czasowe metody wariacyjne wymagają dyskretyzacji metodą elementów skończonych całej domeny przestrzenno czasowej i tym różnią się od metod wykorzystującej schematy kroków czasowych. To podejście dostarcza naturalnych struktur dla problemów przepływu w poruszających się obszarach i pozwala na równoczesne zrównoleglanie $\mathrm{i}$ adaptację zarówno $\mathrm{w}$ przestrzeni jak i w czasie. Typowym rozwiązaniem dla przepływów nieściśliwych jest zastosowanie tego samego stopnia wielomianu dla prędkości i ciśnienia, co wymaga wprowadzenia metod stabilizacji $\mathrm{w}$ celu skompensowania niedoboru infimum-supremum takich par. W niniejszej pracy rozszerzono sformułowanie przestrzenno czasowe o ideę elementu Taylora-Hooda dla równań (Naviera-)Stokesa. Poprzez zastosowanie kwadratowej interpolacji dla prędkości i liniowej interpolacji dla ciśnienia, zarówno w przstrzeni jak i w czasie, uzyskano stabilną metodę elementów skończonych dającą optymalną zbieżność dla ciśnienia, prędkości i naprężeń. 